DOI: $10.2478 /$ rjp-2019-0003

Rom J Psychoanal 2019, 12(1):17-38

Rom J Psychoanal

\title{
"LISTENING WITH A THIRD EAR" - IS THERE A KEY TO THE ARCHAIC?
}

Eike Hinze $e^{3}$

Abstract: How can the analyst get access to early preverbal material in the patient's internal world? The author proposes a dynamic view of memory with no strict boundaries between different memory systems as particularly suitable for clinical purposes. Being in a state of evenly suspended attention and feeling open to all the verbal and non-verbal signals emanating from the patient, the analyst has the best opportunity to approach the archaic traces of early experiences even in the preverbal phase of development. Mutual enactments between analysand and analyst may help in this process as well as understanding the unconscious roots of the artistic activity of some patients. The author tries to illuminate his thoughts using the analysis of a children's book of the nineteenth century and examples from three psychoanalytic therapies.

Keywords: archaic, pre-verbal, early development, mutual enactment, memory, unconscious.

33Berlin Karl-Abraham-Institute (DPV/IPA); e.f.hinze@t-online.de 


\section{Introduction}

As psychoanalysts we know that many psychic traumata occur in early childhood, at an age when the infant is not yet able to use the tool of language and to think symbolically. These abilities are not there from the very beginning. They need time to develop during the first two years of life. Often this early, archaic phase is referred to as the preverbal or pre-symbolic stage of development. How can we access a patient's traumatic experiences which he underwent in this archaic time of his life when he finally as an adult consults a psychoanalyst? It is exactly these early times of suffering in a patient's life that are often, if not always, indispensable to be reached in order to ensure a satisfying psychoanalytic process and a stable therapeutic outcome.

\section{"The Struwwelpeter"}

Introducing the subject of my paper I first want to leave aside theories about early infantile development and current concepts regarding the development of language, symbolic thought and memory. This theoretical background will be dealt with later on. I want to invite the reader to embark on a journey into the world of children's books. Let's examine the world-famous book of "Struwwelpeter", first translated into English by Mark Twain under the title "Slovenly Peter" and known in French as "Pierre l'Ébouriffé". Perhaps some readers have read it in their childhood, or parents and grandparents may have read it to them.

The English Wikipedia introduces the book as follows: "Der Struwwelpeter" ("shock-headed Peter" or "Shaggy Peter") is an 1845 German children's book by Heinrich Hoffmann. It comprises ten illustrated and rhymed stories, mostly about children. Each has a clear 
moral that demonstrates the disastrous consequences of misbehaviour in an exaggerated way. ${ }^{[4]}$ The title of the first story provides the title of the whole book.

The above-mentioned author Heinrich Hoffmann was an openminded, politically and socially active psychiatrist who wrote children's books and lyrics. The "Struwwelpeter" was meant as a Christmas present for his three-year-old son. The following thoughts about "The Struwwelpeter" are mainly borrowed from an excellent psychoanalytic book with the title "Der Struwwelpeter - Poetry and Interpretation" written by my German colleague Anita Eckstaedt (1998).

At first, I would like to give a short introduction to the Struwwelpeter (2019) by choosing a selection of the stories. In all of the pictures shown in the book, which were drawn by Hoffmann himself, the missing mother is a central element. From the biography of Heinrich Hoffmann we know that his mother died when he was eight months old.

The title page of the book depicts the Struwwelpeter. In the translation by Mark Twain, the rhyme beneath the picture reads as follows:

See this frowsy "cratur"

Pah! it's Struwwelpeter

On his fingers rusty,

On his two-head musty,

Scissors seldom come;

Lets his talons grow a year

Do any loathe him? Some!

They hail him "Modern satyr -

Disgusting Struwwelpeter."

${ }^{4}$ https://en.wikipedia.org/wiki/Struwwelpeter\#cite_note-1 

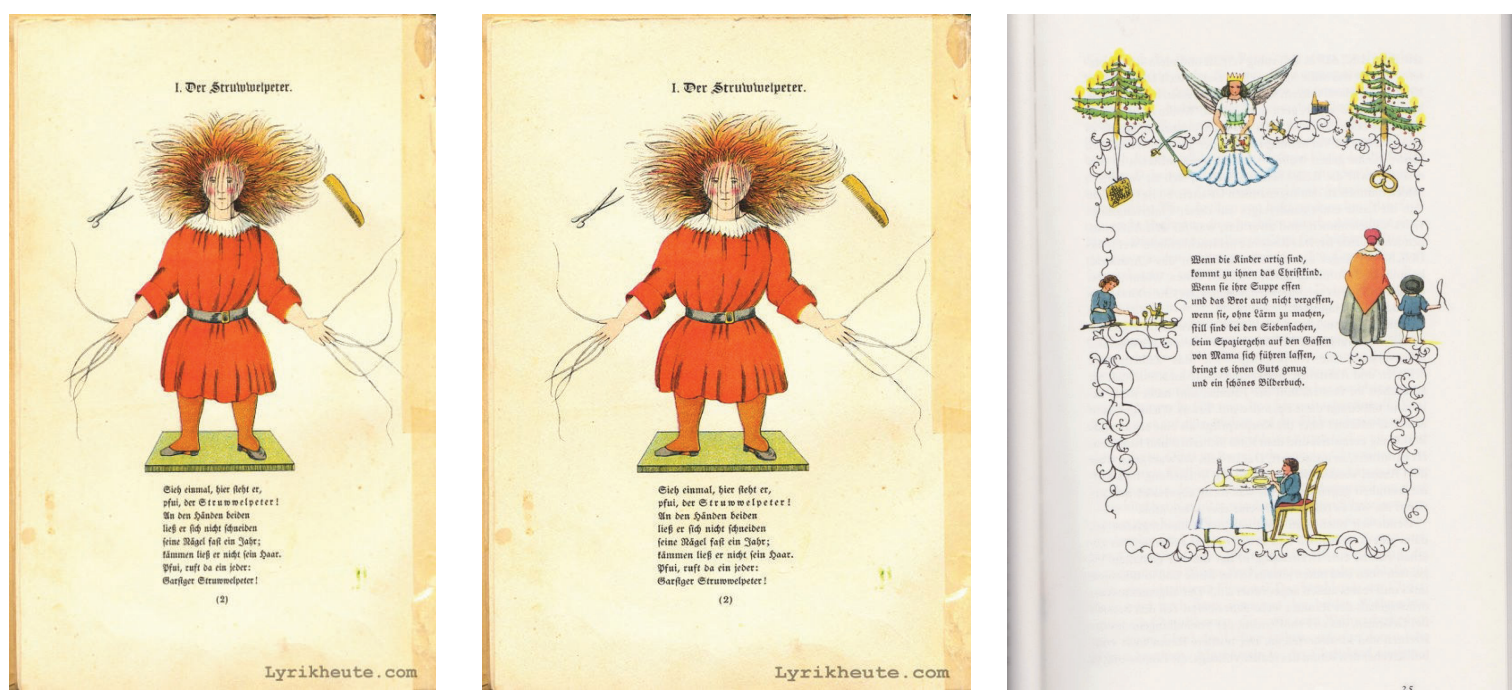

The conscious objective seems to be clear. Children were admonished in a funny way to have their hair and finger nails cut. But one can also interpret the picture as a little boy who has no mother caring for his basic needs.

This view is confirmed if one looks at Struwwelpeter's face. It looks rather sad. And the strands of hair covering his face are more like tears. Interestingly, Hoffmann later on changed this sad facial expression in his drawings.

On the first page of the book one sees a boy who is eating and playing alone. He is walking with his mother shown from behind. She seems to be the absent mother who is waiting for him as an idealised angel figure in heaven.

One story is about "Ugly Frederik". In his anal aggression he is torturing and killing flies, birds and cats. He even beats the maid. She may represent his mother who left him. Finally, the dog bites his leg after Frederik tried to beat it. Frederik has to stay in bed, and there is no mother caring for him. Only a neutral father figure is standing at his 
bedside and administers him a bitter medicine. There is no mother helping him to master and sublimate his drives.
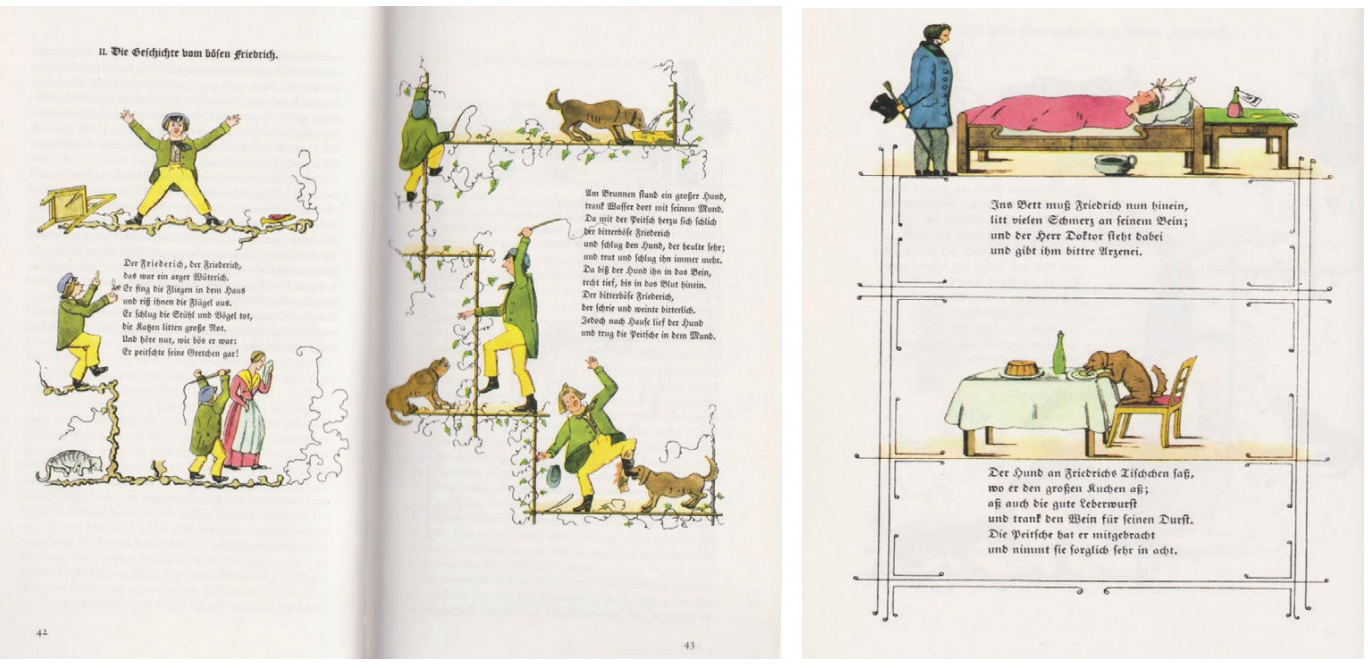

In another story the leaving mother admonishes the boy not to suck his thumbs. He does not obey and suddenly the tailor enters the room and cuts off his thumbs. The displacement from the genital to the oral sphere is obvious. Behind the tailor the image of the castrating mother appears. A loving mother is no longer available.

In the following story, Kaspar refuses to eat and finally dies. There is no nourishing mother. At the end the boy is uniting with mother earth in his grave.

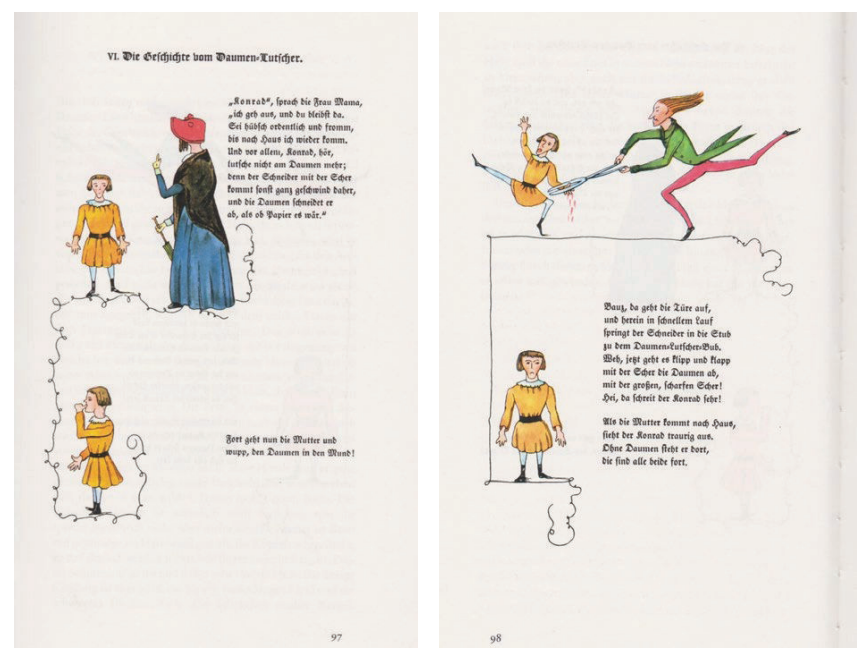


In the last story a boy is blown away by the storm and carried away into heaven. This short story expresses his longing for the absent mother and his wish to be reunited with her in heaven. Now he might be flying to the angel-like figure on the first page.

I would like to quote the full text beneath the pictures because, like in the other stories, the rhymed verses show the superficial educational purpose.

Underneath, however, the sad boy longing for his dead mother can be felt.
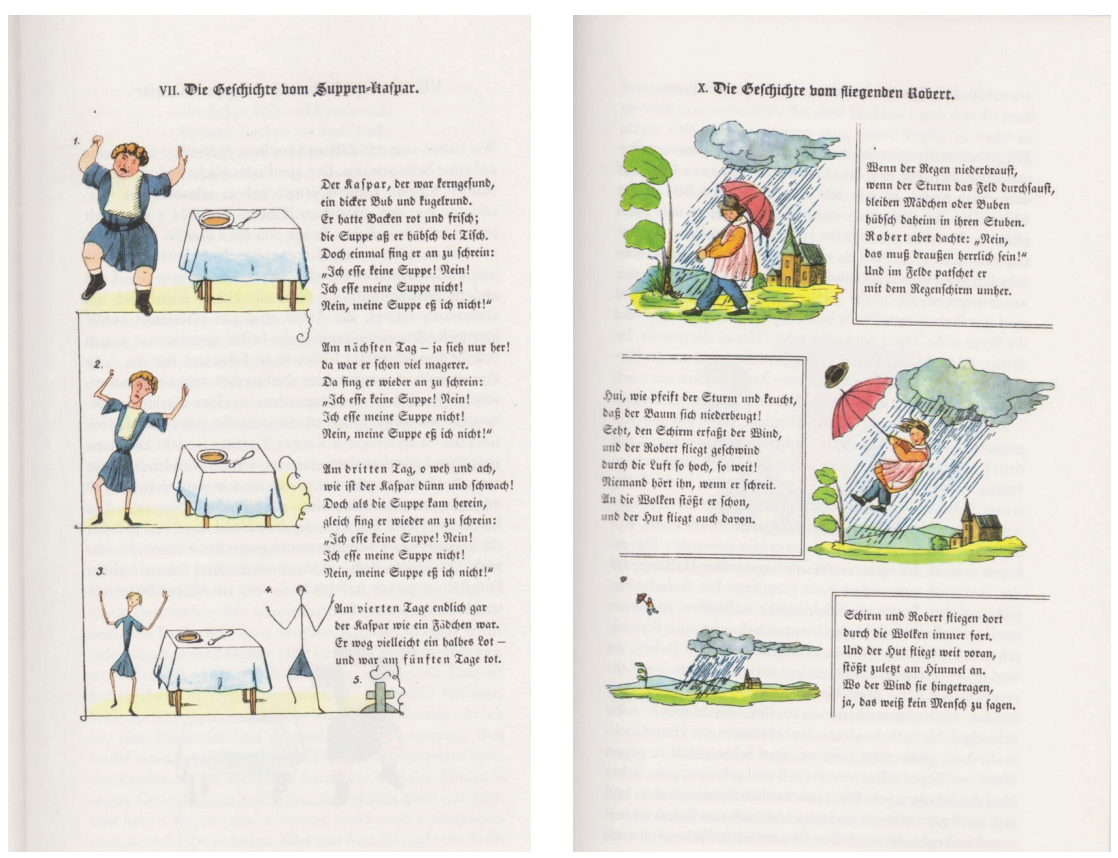

When the rain comes down a-dash,

When the storms the meadows lash,

Boys and girls stay snug at home

Preferring to let others roam;

But Roberts thinks, "Ah, me,

It's just the time outside to be!" 
and so, umbrella'd safe and sound,

Takes to the fields and slops around.

My! how shrieks the windy storm,

and how the big tree bows its form!

Hoho! the 'brella's caught the breeze,

And Robert sails above the trees!

Above the houses, church and steeple,

and out of sight of all people!

Above the clouds he spins at last,

His hat is gone, and he's aghast!

And so he sails and sails and sails,

Through banks of murky clouds, and wails,

And weeps and mourns, poor draggled rat,

Because he can't o'ertake his hat.

Oh, where on high can that hat be?

When you find out, pray come tell me.

The above-mentioned interpretations represent only a short-hand version of the thorough analysis done by Anita Eckstaedt in her book (1998). They are corroborated by the story of Hoffmann's life. Three years after his mother's death, his father married again. Hoffmann wrote the "Struwwelpeter" at the age of 34, when he had just surpassed the age of his mother when she died. His son was three years old, and his wife expected her second child. This impending birth threatened his son with the loss of his mother. And, to top off these anniversary reactions, Hoffmann was pregnant with his book around Christmas, the time of his mother's death. These circumstances and, above all, the content and the form of the stories seem to unequivocally demonstrate that the author 
dealt with the early loss of his mother. However, his attempt to work through his early childhood occurred absolutely unconsciously. The verses about the little boy flying into the air clearly show this. During his whole lifetime he seemed to have remained unaware of the impact his mother's death had on his life and development. On the contrary, he lovingly praised his stepmother who "faithfully loved him and nurtured and cherished him", whereas he wrote that "his biological mother with her morbid impulsive character couldn't have proved more faithful than his stepmother (Eckstaedt, 1998, p.175). We know that Heinrich's father had cared for him reliably after his wife's passing. But there was no space for the young child's suffering and mourning. The little boy was educated in the spirit of work and dutifulness.

An apparently good early mothering by his biological mother and an innate or epigenetically developed creativity enabled Heinrich Hoffmann to symbolically and artistically express the impact of his early trauma on his development. However, he did not have the chance to consciously work through these early stages of his development in a psychoanalytic treatment. But how was it possible that he gained symbolical access, although unconsciously, to his early experiences that occurred in his preverbal and pre-symbolical stage of development? How could this happen if one considers the nowadays frequently favoured theories of two distinct memory systems, separated from each other, one for implicit and nonverbal and the other for explicit episodic experience? Before addressing this issue, I will draw on my clinical practice.

\section{Mr. A}

Mr. A started a psychoanalytic psychotherapy with two weekly sessions face to face at the age of 73 , which ended four years later. Some 
years earlier he had already contacted me because of severe marital problems, whereupon I recommended him a couple-therapy. When we met again, he had started a relationship with a younger woman, but got severely depressed and experienced a total loss of orientation in his life. He realized, for the first time, how anxious and insecure he had felt throughout his entire life. When I recently, after having finished his therapy, contacted him again and asked him for his consent to speak and write about his treatment, he agreed in an email and uttered his curiosity. In the meantime, he went through his diaries and thought that a good title for them would be "Intra due cibi". This is a quotation from Dante's Divine Comedy (Paradise, Canto IV):

Between two kinds of food, both equally

Remote and tempting, first a man might die

Of hunger, ere he one could freely choose.

You may guess the central problem of this man? He had two mothers. His mother wanted to abort him and crossed the border to the neighbouring country where abortions could be easier performed. The woman who owned the hotel where she stayed had desperately tried to get pregnant herself, but always unsuccessfully. She therefore proposed to the pregnant woman to deliver the child and to give it to her. His biological mother agreed, and so he stayed from the first days of his life with his adoptive mother. He does not know whether his mother actually sold her child to the adoptive mother. During his second year of life his biological mother stayed for some time in his adoptive home once again because she was needed as a helping figure during a severe illness of his adoptive father. Only after his adoptive mother's death did he learn that 
letters from his mother were retained and hidden from him by his adoptive mother. When he tried to contact his mother at the age of 40 , she refused. Much could be said about his further development, but I want to restrict myself mainly to this traumatic beginning of his life. $\mathrm{He}$ was a rather solitary child who, from his outer appearance, did not fit into the group of his peers. His adoptive mother was a rather paranoid personality who actually became psychiatrically paranoid later on. His adoptive father died in an accident when he was 11 years old. His biological father never appeared as a real person. Later on, Mr. A led a rather migratory life and became an artist in the field of movies, videos and photography. He had many short-term relations with women. One of his partners gave birth to a daughter. The relationship with her became a focus in the therapy. Finally, he settled down in Europe and became a teacher at an arts academy.

From the beginning of therapy, problems of countertransference played a major role. Mr. A had great difficulties in getting in contact with his internal world. Sessions often seemed to remain superficial, and I sometimes lost interest and got distracted. In the grips of a massive projective identification I became identified with the disappearing and abandoning mother who wanted to abort him. At first, I could not think about these dynamics. The drama of the beginning of his life escaped my attention. I was too focussed on his age and his conflictual actual life situation. However, again and again, specimens of his artistic activity which he shared with me, and his enactments with his mistress, helped me get in touch with his early experiences. The latest examples of this kind are his quotations of the Divine Comedy and a remark he made about his diaries in the same email. He drew my attention to the fact that he often used the sentence "I went across the line", which meant to cross 
the border between the two countries. Examples hinting at the difficult and confused situation between his two mothers. As the treatment went on, he grew more and more aware of the connections between these quotations and thoughts and his internal world. In the following sentences I want to give some examples of his nonverbal and artistic communications that helped me better understand him and his early suffering. Only my meeting him in the archaic and nonverbal realm of his early experiences made it possible for him to better adjust to his actual life situation and to find a realistic solution to his feeling confused between two women.

In the very beginning of therapy, he gave me a print of a poem written by Ted Hughes after his wife Sylvia Plath had committed suicide. Only later on it dawned upon me that he wanted to communicate to me something about his early childhood. It is a poem about the loss and despair of a husband who did not understand why his wife left him so cruelly. She killed herself while her children slept in the adjacent room.

Several photographs taken by Mr. A himself accompanied the whole course of therapy.

The first photograph (the only one not taken by Mr. A but chosen by myself from the internet) shows the birthplace of Mr. A, which is literally cut through by a wall constituting the border. It represents a concretization of his remark of "crossing the line".

The second photograph is a specimen of his temporary obsession with taking photos of discarded cigarette butts. I understood them as showing me the utter isolation and feeling of being lost and thrown away that dominated his internal life at the beginning of therapy. 

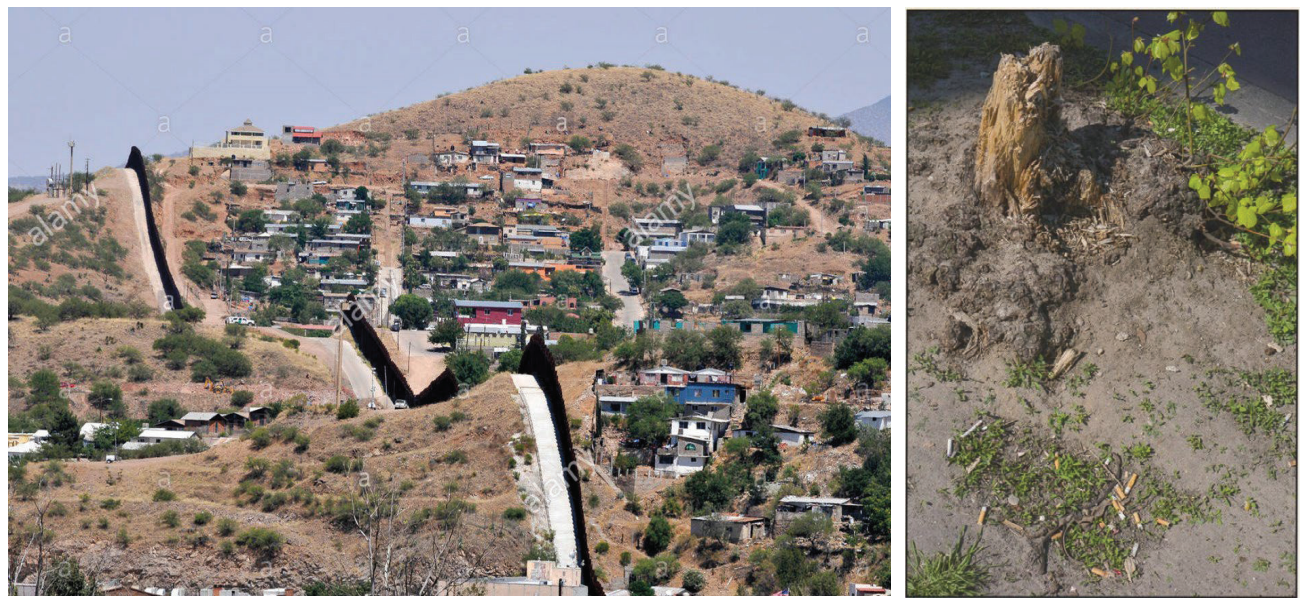

The third photograph shows a lonely tree stump out of which small branches with green leaves are growing. Here again his loneliness and isolation are demonstrated, but without the thrown away cigarette butts and with signs of germinating hope.

The fourth photograph stems from a later period in therapy. It shows a demarcating rope in a forest. I understood it as an attempt to create a structure in his internal world and to differentiate his situation between two mothers.
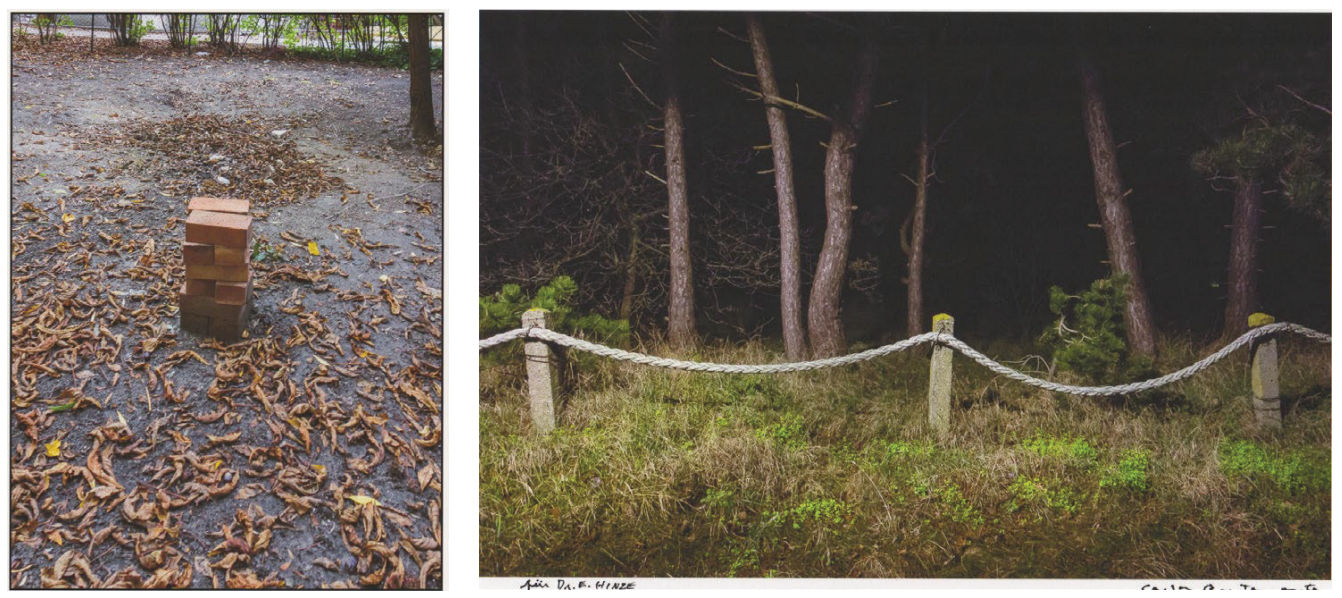
There is also a photograph showing a flower blooming in the fence. I understood this picture as a first sign of burgeoning reparation. The last photograph shows a hugging couple amidst torn billboards. Here he is able to show the intimate encounter of one man and one woman.

Initially, Mr. A could only enact his internal situation between two mothers by feeling torn between two women. His actual quotation of Dante's version of Buridan's donkey refers to this dilemma. The poem by Ted Hughes expressed the utter despair about an object loss. He could not, however, connect these verses with his own experience. The sequence of his pictures then shows not only his progression towards a deeper understanding of himself, but it also represents his attempts to communicate this development to me. It helped me better understand his internal world and fostered a deeper link between patient and analyst. His artistic photographs, of course, only highlighted certain steps in the analytic process which proceeded as a constant stream with numerous meanders.

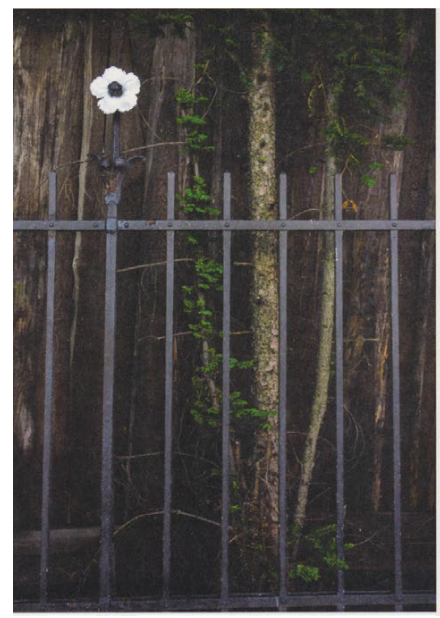

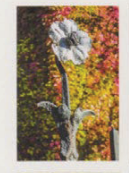
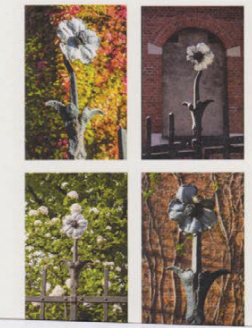
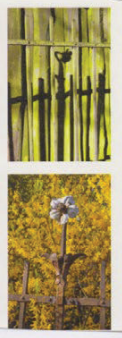

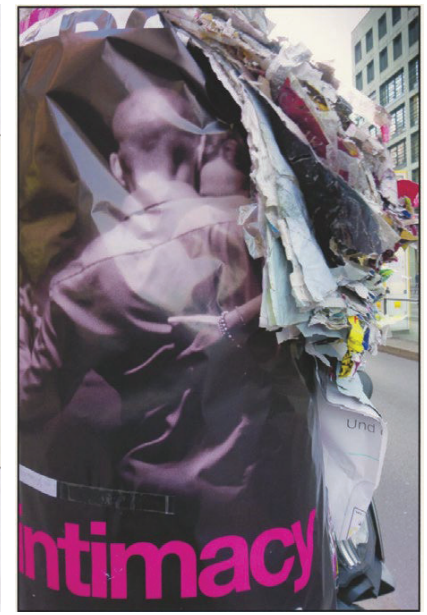




\section{Theoretical considerations}

How can we conceptualize the process of getting into emotional contact with the drama and the suffering of his early childhood? His mother's attempts to abort, i.e. to kill him, occurred before his birth. $\mathrm{He}$ does not know whether his biological mother stayed at the adoptive mother's hotel or for how long. In his second year of life she seems to have worked there for a short time. How have these early experiences been laid down in his memory systems? The assumption of two strictly separated memory systems, which are linked to different brain structures - the implicit or procedural and explicit or episodic memory - does not sufficiently account for the frequent transitions between these two systems (Gaensbauer, 1995; Mancia, 2006). In the patient's frequently changing relationships with women whom he finally left because he felt a negative impact on him, one may see the procedural repetition of the early relationship with his biological mother. In the therapy, however, he gained symbolic access to his early trauma and could finally modify his experience and behaviour in relationships (see also Coates, 2016). Heinrich Hoffmann found this access without therapy by means of his artistic creativity, although without becoming able to consciously work it through. In contrast to assuming two strictly separated memory systems, I favour the concept of "embodied memory", stressing a more holistic view of memory. Nowadays we know that remembering cannot be conceptualized as just retrieving memory traces from memory storage systems (Leuzinger-Bohleber, 2002). Remembering is a far more active process by which memory traces are constantly adjusted to the present and thereby modified. The psychoanalytic concept of "après coup" or "Nachträglichkeit" reflects this process. 
We often meet patients who suffered severely or were traumatized as infants, but had not been able in later life, like Hoffmann, to translate their early experience in symbolic language and make it amenable to further psychic working through. Their archaic life lies buried in the depths of their souls, split off from the possibility of conscious elaboration. It is necessary that we get access to this archaic preverbal realm for the cure. But how can we accomplish this task? All concepts of psychoanalytic theory or practice deal with this question. Listening to their theoretical language, one may get the impression that they strongly differ in theory and practice. However, a glimpse into the consulting room may show that these differences are diminishing in the immediacy and heat of the analytic encounter. The following list outlines different approaches in theory and practice. It is not complete, and there are overlappings.

1. Analysts may think they have a special sense from unconscious to unconscious like the Third Ear, which Theodor Reik (1948) introduced into psychoanalytic discourse. Freud may be similarly understood when he wrote: "To put it in a formula: he must turn his own unconscious like a receptive organ towards the transmitting unconscious of the patient. $\mathrm{He}$ must adjust himself to the patient as a telephone receiver is adjusted to the transmitting microphone. Just as the receiver converts back into sound waves the electric oscillations in the telephone line which were set up by sound waves, so the doctor's unconscious is able, from the derivatives of the unconscious which are communicated to him, to reconstruct that unconscious, which has determined the patient's free associations" (S. Freud 1912, 115). But we know how painstakingly Freud used secondary process thinking to decipher unconscious content 
in the material of his patients. I adhere to Freud's clinical stance that there is no simple intuitive access to a patient's unconscious.

2. Analysts may be convinced that the archaic and pre-symbolic realm of the psyche is inaccessible and may refrain from attempts to understand these processes and concentrate instead on analysing the vicissitudes of oedipal conflicts.

3. Analysts may assume the existence of a kind of pre-symbolic thinking and fantasizing from the very first moments of life. They then conceptualize a more coherent and steady line of development of thinking and fantasizing with no abyss between preverbal and verbal experience (Coates 2016, Hinshelwood 2007).

4. Bion's theory (Grinberg, 1985) of Beta-elements transformed by mother's rêverie and projective identification into alpha-elements is another attempt to cope with the questions and problems of early development of thinking and experiencing.

5. One may resort to findings of neuro-science and understand and conceptualize the patient's material in terms of different modes of memory, e.g. implicit versus explicit or declarative versus procedural (Fonagy 1999).

6. There are analysts who think that preverbal experience can make itself only known to the analyst via action or mutual enactments.

7. Relational analysts may think that interpreting and verbalizing of archaic material in the session is less important than the actual experience of the analytic encounter with its emotionally correcting potential.

8. Last but not least, the Lacanian theorizing offers a very different perspective, assuming an identical structure of the unconscious and language. 
My position is that I do not believe in a privileged, onedimensional access to the Archaic. There is not such a thing as a Third Ear. However, Freud's discovery of the interplay of free association and evenly suspended attention has equipped us with a subtle instrument to approach the Unconscious and the non-verbal and senso-motoric realm of the psyche. We can come closer to this realm by not only listening to the content of language, but to the way the patient is talking, to the prosody of his speech. And there is an abundance of other non-verbal signs if we use other channels of perception. There is body language, actions, psycho-somatic-reactions - all in the patient and in our self as messages of our countertransference. In the analysis of Mr. A it was his creative activity and my countertransference that paved the way to his infantile preverbal experience.

By means of another case I now want to illustrate how a traumatically split off part of the psyche influenced the analytic process. Although the trauma occurred later in life, there was an intricate connection with the preverbal life of the patient.

\section{Mrs. B}

Mrs. B is now in her mid-fifties and has been in analysis with me for many years. The analysis is being conducted with three weekly sessions. She could only remember a few stories from her childhood. Her early years seemed to be devoid of liveliness. Her childhood memory was characterized by her ability to depict a very clear vision of her parental home. She could remember slightest details of the furniture. Despite this, she could not envision any people inhabiting the rooms. In her memory she saw the house totally empty. I understood this as 
representing her depressive mother, who had followed her husband into a foreign country and had apparently never adjusted to the new environment. She died when Mrs. B was eleven years old. The onset of her final illness was rather dramatic. Mrs. B cared for her several months without much assistance. As a biographical fact the mother's death appeared in Mrs. B's associations, but just as a fact, without any emotion. This was characteristic for the whole course of analysis during the first years. Mrs. B had some memories of her childhood, but could not connect them emotionally to her current situation in life or analysis. Sessions after sessions were filled with stories about her stereotypically repeating relational conflicts. In the countertransference I felt like the shadowy dead mother. But then Mrs. B slowly became livelier and more thoughtful. One day before Christmas she suddenly felt the impulsive wish to bake cookies. She had never done this before, but intuitively knew how to do it. Suddenly, she remembered the day when her mother fell ill with a dramatic attack of pain. This had occurred in the midst of their Christmas baking. She successfully finished baking the cookies and brought some to me in the session as a present. I accepted, ate them and found them delicious, which I told her next day. This mutual enactment was a turning point in her analysis. Her memories became more emotional and she could approach the depressive mother of her childhood. The analysis became livelier and more emotional. What had happened? As an outcome of a slowly proceeding and deepening psychoanalytic process she gained access to the traumatizing illness and ensuing loss of her mother. This trauma had been hitherto kept split off her symbolically thinking and remembering psyche. And, like through a bottleneck, she became able to emotionally reach out for her early childhood. I think this example puts into question the assumption of 
different memory systems that are totally kept apart from each other. Preverbal and verbal communication merged. I think that my enactment (eating the cakes) helped me empathize with the senso-motoric experience of Mrs. B. This example may also demonstrate that dealing with severely traumatized patients always touches upon questions of nonverbal representation and communication, notwithstanding the age at which the trauma occurred.

\section{Miss C}

My last clinical example deals with a young woman, Miss C, who is also an adopted child. She had so far cherished the conviction that her mother had put her up for adoption because she could not marry the father for religious reasons. Under the protection of the beginning analysis she dared to meet her biological mother for the first time and received the disappointing news that her mother had given her away because she rejected having a baby and caring for it. Miss $\mathrm{C}$ is still in the initial phase of her analysis. Soon after the start she bought a young dog which she often brings with her into the sessions. Because the dog does not like to be cuddled unexpectedly and starts biting in public, she purchased a muzzle for it. Without any doubt the animal is representing herself. This also becomes apparent in the session when Miss $\mathrm{C}$ is cuddling the dog and playing with her in a way which leaves me with a very irritated body feeling and excites the dog more than it calms her down. I understood this observation in connection with my countertransference as reflecting a disturbed early attachment between patient and adoptive mother. The treatment is conducted in a foreign language, Miss C's mother tongue. Miss C often speaks so fast in a certain dialect that I sometimes have difficulties following and 
understanding her. I feel like her adoptive mother, trying very hard to adapt to this foreign child. So, this therapy is dominated from the very beginning by nonverbal communication and mutual enactments. They serve me as cues which help me draw closer to her early experience in life. With Miss C I finish my little series of case vignettes.

\section{Conclusion}

I have used an example from literature and two of my analytic cases to demonstrate how I try to get access to the archaic infantile and unconscious realm of a patient's internal world. The notion of a "Third Ear" that T. Reik introduced into the psychoanalytic discourse appears very appealing but is misleading in so far as it suggests the possibility of getting a direct intuitive contact with the Archaic. In contrast I outlined my approach of understanding the unconscious communication between analysand and analyst and mutual enactments occurring in the session. This process presupposes a complex conceptual background on the side of the analyst. Although I have stressed the importance of nonverbal communication in the analytic process, we finally have to formulate verbal interpretations or hypotheses that we offer to the patient, inviting him/her to think about them.

In the classical analytic setting, we do not see the patient's face and abandon all signals emanating from it. Doesn't this contradict the emphasis on all non-verbal signals? Staying in constant eye contact, however, impedes the development of a regressive relationship between analysand and analyst. Furthermore, it impedes the development of free association and evenly suspended attention. All the above-mentioned verbal and non-verbal signals of the patient and the corresponding reactions of the analyst are embedded in this relationship. The analyst is 
co-creator of the analytic field between the analysand and himself, which constitutes the fertile ground necessary for giving birth to all the phenomena he needs in order to approach the archaic dimension of the patient.

\section{REFERENCES}

COATES, S.W. (2016). Can Babies Remember Trauma? Symbolic Forms of Representation in Traumatized Infants. $J$ Am Psychoanal Assoc, 64(4):751-776.

DANTE, A. (1320). Divine Comedy. Paradise, Canto 4. https://digitaldante.columbia.edu/dante/divinecomedy/paradiso/paradiso-4/ (20.2.2019).

ECKSTAEDT, A. (1998). “Der Struwwelpeter” Dichtung und Deutung [,Der Struwwelpeter” Poetry and Interpretation]. Suhrkamp Verlag, Frankfurt am Main.

FREUD, S. (1915) Recommendations to Physicians practicing Psychoanalysis. SE XII, pp. 109-120.

GAENSBAUER, T.J. (1995). Trauma in the Preverbal Period: Symptoms, Memories and Developmental Impact. Psychoanal Study Child 50:122-149.

FONAGY, P. (1999). Memory and Therapeutic Action. Int J Psychoanal 80(2):215-223.

GRINBERG, L. et al. (1985). Introduction to the Work of Bion. A. Wheaton \& Co., Exeter.

HINSHELWOOD, R.D. (2007). The Kleinian Theory of Therapeutic Action. Psychoanal Q,1479-1496.

HOFFMAN, H. (11.2.2019). www.struwwelpeter.de 
LEUZINGER-BOHLEBER, M., PFEIFER, R. (2002). Remembering a Depressive Primary Object: Memory in the Dialogue Between Psychoanalysis and Cognitive Science. Int J Psychoanal 83(1):3-33.

MANCIA, M. (2006). Implicit Memory and Early Unrepressed Unconscious: Their Role in the Therapeutic Process (How the Neurosciences Can Contribute to Psychoanalysis). Int J Psychoanal 87(1):83-103.

REIK, T. (1948). Listening with the third ear: The inner experience of a psychoanalyst. Farrar, Straus \& Cudahy, New York. 